\title{
Political Ambition and Legislative Behavior in the European Parliament*
}

\author{
Stephen A. Meserve Daniel Pemstein William T. Bernhard \\ meserve@uiuc.edu \\ dbp@uiuc.edu \\ bernhardQuiuc.edu \\ University of Illinois at Urbana-Champaign \\ Department of Political Science \\ 361 Lincoln Hall \\ 702 S. Wright Street \\ Urbana, IL 61801 \\ Tel: 217.333 .3881 \\ Fax: 217.244 .5712
}

\begin{abstract}
Members of the European Parliament (MEP) typically follow one of two career paths, either advancing within the European Parliament itself or returning to higher office in their home states. We argue that these different ambitions condition legislative behavior. Specifically, MEPs seeking domestic careers defect from group-leadership votes more frequently and oppose legislation that expands the purview of supranational institutions. We show how individual, domestic-party, and national level variables shape the careers available to MEPs and, in turn, their voting choices. To test the argument, we analyze MEPs' roll-call voting behavior in the 5th session of the EP (1999-2004) using a random effects model that captures idiosyncrasies in voting behavior across both individual MEPs and specific roll-call votes.
\end{abstract}

*We thank Brian Gaines, Jude Hays, Robert Pahre, Kevin Quinn, Tom Rudolph, and Guy Whitten for helpful assistance. We also acknowledge the funding support of the European Union Center at the University of Illinois. 
Politicians are ambitious. Some legislators wish to remain in their current positions for multiple terms, others aspire to other offices, and still others expect to serve in politics for only a short time (Schlesinger 1966). Those career ambitions shape behavior. A legislator's expectations about future office affect the choices she makes while serving in her current position (Hibbing 1986). Demonstrating empirical support for the importance of political ambition, however, is not straightforward. While research has focused on behavior across legislatures with a variety of career ladders (see e.g. Black 1972, Rhode 1979, Epstein, Brady, Kawato \& O'Halloran 1997, Samuels 2003), those studies center on a single country, limiting the possible variation in career-oriented behavior. Since only a small number of other positions are likely to arouse the ambitions of serving legislators, it is difficult to disentangle how the characteristics of the legislature, its members, and the opportunity structure interact to influence legislative behavior. ${ }^{1}$

We take advantage of a unique institutional laboratory to investigate how ambition affects vote choice: the European Parliament (EP). The EP houses politicians from all member states of the European Union (EU), each with a different set of national political institutions, party systems, and political opportunity structures. Members of the European Parliament (MEP) typically follow one of two career paths (Stolz 2001, Scarrow 1997). Some MEPs prefer to advance within the EP itself, gaining seniority and access to key leadership positions. Other MEPs view their time in the EP as a valuable stepping-stone to higher office in their home state. We argue that these different career ambitions condition legislative behavior within the EP. Those MEPs seeking to remain in the EP further their careers by pleasing EP group leaders and will work to expand the authority of Europe's supranational institutions relative to member-state governments. MEPs expecting to return to domestic political positions, in contrast, have less reason to abide their parliamentary groups. They also have incentives to preserve member-state powers and prerogatives at the expense of supranational institutions. Because MEPs have the opportunity to pursue a variety of future offices, their behavior illuminates the role of institutional variables in the ambition calculus - such as 
electoral institutions and political party characteristics - which do not generally vary within national legislatures.

We contend that individual, domestic-party, and national level variables shape career opportunities available to MEPs and, in turn, their legislative behavior. To test the argument, we analyze MEPs' roll-call voting behavior in the 5th session of the EP (1999-2004). The data indicate substantial variability in behavior across both individual MEPs and roll-call votes. Traditional approaches typically consider only across-legislator variability and ignore the differences between votes. We demonstrate that across-vote differences can significantly outweigh between-legislator variation. Ignoring either factor may lead to overconfidence in the results. Therefore, we use a crossed random-effects model to account for idiosyncrasies in voting behavior across both individual MEPs and specific roll-call votes. Substantively, the results indicate that nationally ambitious MEPs change their voting behavior in anticipation of national elections, demonstrating how politicians' time horizons interact with their progressive ambition. Further, MEPs planning moves to national office oppose legislation that expands the purview of supranational institutions, strengthening their expected future offices and prioritizing future constituencies. The personal ambition of MEPs, therefore, has a critical effect on European lawmaking and the pace of integration.

\section{Political Ambition and the European Parliament}

Americanist scholars first argued for political ambition's important role in conditioning legislator behavior (Schlesinger 1966, Black 1972, Rhode 1979). They contended that "almost all elected officials have progressive ambition" and hope to move upward to more powerful, prestigious offices (Copeland 1989, 552). To ensure success, these politicians make policy choices that satisfy not only their own current constituents, but also potential future constituents (Hibbing 1986). Politicians anticipating only minor chances to move to more important offices, however, have little incentive to support legislation specifically targeting future constituents. Instead, they seek to maximize the influence of their current position by 
climbing the legislature's internal hierarchy and expanding the policy authority of those institutions (Hibbing 1999, Squire 1988). In either situation, ambition strongly shapes current behavior. More recently, scholars have applied these insights to legislatures in other countries, showing how the institutional environment determines opportunities for advancement (Samuels 2003, Carey 1996, Epstein et al. 1997, Cox, Rosenbluth \& Thies 2000).

The institutional structure of the EP is unique in how it shapes legislative careers. MEPs are elected in national-level elections to serve a five year-term in the EP. Currently, all member states use proportional representation in "European" elections. National-level parties control nominations to European elections. Candidates in EP elections, therefore, owe allegiance to their national party. Further, if a candidate seeks to return to domestic politics, she will have to seek her party's nomination in the domestic election. Once elected to the EP, however, MEPs sit in "groups". Groups are composed of MEPs from different parties across member states. The largest group in the 5th EP, the Group of the European People's Party (EPP-ED), includes members from more than 30 national-level parties. These groups structure the agenda and determine parliamentary leadership within the EP, much as political parties do in national-level parliaments.

In general, MEPs have strong incentives to vote with their group leaderships. While EP groups have little control over electoral nominations, they exert impressive influence within the EP itself. Group leaders dole out committee assignments, control the speaking agenda within the parliament, propose bill amendments, and nominate MEPs to the Parliamentary Bureau, the body responsible for the EP's budget and agenda. Groups employ coordinators - essentially whips - who signal leadership preferences to backbenchers during floor votes. These coordinators monitor how MEPs vote, potentially allowing them to punish recalcitrant MEPs. Thus, MEPs have good reason to consistently toe the group line.

Nonetheless, ambition affects the willingness of MEPs to follow their group. MEPs face a distinct choice of career paths. Descriptive evidence shows that some MEPs desire positions of power within European institutions while others seek a return to domestic office. In 
the years following the advent of direct election to the $\mathrm{EP},{ }^{2}$ it was conventional wisdom that MEPs were strongly motivated by a wish to return to national politics. To test this, Scarrow (1997) compiled data on pre- and post-EP offices for MEPs elected between 1979 and 1994. She observes that, over time, the EP attracted more legislators interested in a European career rather than in returning to a domestic office. Stolz (2001) uses similar data to calculate "exchange rates" between domestic and European levels of legislative office. His results also detail the existence of a European career track, suggesting that "parliaments on the regional and European level also function as career arenas in their own right" (2).

We contend that ambition influences MEPs' legislative behavior. Specifically, MEPs cast their legislative votes to maximize their career expectations. For MEPs focused on advancing within the EP, the primary constituency is the group leadership. The group leadership controls their access to resources and prerogatives within the EP. MEPs on national career arcs, on the other hand, must prioritize home constituency preferences, especially those bodies responsible for candidate nominations. When group leadership and domestic-level constituency clash, nationally ambitious MEPs look to the domestic interests to determine their behavior. MEPs with national ambitions, therefore, are more likely to vote against their group leaders than MEPs inclined to build a career at the European level.

Further, we expect these differences to be particularly pronounced for issues relating to the power and authority of European institutions. MEPs who plan to remain in Brussels benefit from stronger European institutions. By expanding the powers of European institutions, careerist MEPs enhance their own influence and prestige as they work their way up the EP hierarchy. MEPs hoping for future national office, on the other hand, need to appeal to domestic parties and voters. They work to advantage member states in terms of policy and spending and to preserve member sovereignty within the structure of EU institutions. Therefore, we expect these MEPs to support fewer powers for supranational institutions. 


\section{Determining Ambition in the European Parliament}

Ambition theory predicts that politicians make decisions based on the potential benefits of alternative offices and the probability of achieving those positions. If opportunities to move up the ladder are plentiful or if politicians think they are likely to succeed, politicians behave in a manner that appeals to future constituents. If there are few opportunities to succeed or if the probability of achieving those positions is low, politicians focus on satisfying the policy demands of their current constituents.

For MEPs, therefore, their behavior reflects a calculation about the relative merits of a career in Brussels against a career in their home country. If an MEP believes that political opportunities in her home state are few, if those opportunities possess only limited importance, or if she has little chance of succeeding in attaining them, then a career in Brussels becomes more attractive. In turn, she is more likely to go along with her parliamentary group and to support policies that enhance the power and influence of European institutions. On the other hand, MEPs may view domestic office as a more attractive career option, one that provides more policy influence than serving as an MEP. If the possibility of a domestic career is relatively high, then MEPs tailor their behavior toward the concerns of national constituents, being both more willing to defy the EP group leadership and more antagonistic toward augmenting the power of European institutions.

We argue that individual characteristics, domestic party structures, and national institutions influence an MEP's career prospects and, in turn, her legislative behavior.

\subsection{Individual Level Variables}

Individual characteristics shape electoral fortunes and the possibility of changing careers.

\subsubsection{Age}

The literature (e.g., Hain 1974) argues that age conditions the effect of ambition on legislative behavior. In the American context, researchers have found that legislators in the middle of 
their careers are more likely to move on to higher office than either junior or senior lawmakers (e.g., Brace 1984).

We argue that age influences the career opportunities of MEPs. For young MEPs, the doors to a successful career either in Brussels or at home are wide open. Young MEPs looking to move up the European hierarchy can pursue group objectives and participate in group activities. In contrast, young MEPs may view their time in the EP as way to prove their worth to their domestic parties by securing EU spending for their member-state and promoting party objectives at the European level. Indeed, some political parties use service in the EP as a way to groom up-and-coming talent, providing potential candidates with valuable legislative experience and an important line on their political resumes.

As MEPs age, however, the opportunities to return to domestic level office diminish. While serving in the EP for a short time may be a benefit to running for domestic office, an older MEP is not as attractive to a national party. Working in Brussels can foster a perception of being out-of-touch with domestic issues. Other potential candidates will have spent the same time in local and regional offices, building ties to constituents and the party hierarchy. In fact, some political parties view MEP positions as a last stop for older politicians rather than a proving ground for up-and-coming candidates. ${ }^{3}$ As candidates age, therefore, the possibility of domestic office diminishes and the appeal of a career in the EP increases. Consequently, we expect middle-aged MEPs will be more likely to toe the group line and support enhanced powers for European institutions.

Finally, as "old" MEPs close out their careers in Brussels, they face the same sort of end-game incentives present in any legislature. With retirement on the horizon, it becomes less important to satisfy group leaders and follow group directives. Instead, the MEP's own ideology and immediate personal goals take greater precedence in shaping behavior.

Therefore, a focus on political ambition suggests that the relationship between age and legislative behavior is curvilinear. MEPs who are neither particularly old nor young are likely past the point of running for national office, but not so far along in their careers that they do 
not strive to improve their standing within the EP itself. These MEPs should be the most likely to support group directives and expansions of EU power. MEPs closer to retirement, however, are relatively immune to group pressure and incentives. These older MEPs are more likely to defect from group votes. At the same time, we expect that they will continue to support the strengthening of European institutions simply because they have served in the EP and may experience the short term benefits from this expansion. Young MEPs face two potential career paths. The possibility of returning home makes them less likely to follow group directives or to support empowering EU institutions. Yet some may simply plan for a career in Brussels. This variation in ambition across junior MEPs attenuates the direct affect of youth on voting behavior.

\subsubsection{Gender}

Women MEPs may have different career strategies than their male counterparts. While many European parliaments, notably in Scandinavia, have made great strides in promoting the representation of women, women typically have fewer opportunities to attain nationallevel offices (IPU 2006). As a result, women may find planning a career in Brussels more appealing. Consequently, we expect women to defect less from group votes and to support pro-European legislation. ${ }^{4}$

\subsection{National Party Characteristics}

The characteristics of an MEP's national party shape career opportunities and, in turn, MEP behavior.

\subsubsection{Size of the National Party}

The size of a legislator's national party affects an MEP's political ambition. On the one hand, MEPs that are members of large and powerful national parties would wield more legislative power if they returned home, implying that a career in Europe might be less attractive than 
to MEPs from small national parties. Under this scenario, one might expect MEPs from large parties to defect from group votes more often.

But while seats in a large party may be more valuable, the probability of serving in them is often smaller. MEPs from large parties have relatively less hope of returning to national politics due to extensive within-party competition for candidate nominations. MEPs face home-party politicians who have built reputations and ties at the local and regional levels. Compared with these politicians, an MEP — serving in Brussels, away from the domestic political scene - may have difficulty building the networks of support necessary to earn a nomination.

For MEPs from smaller national parties, in contrast, seats in the national party may be less valuable, but serving in the EP may enhance a potential candidate's stature within the party. Smaller parties have fewer domestic-level opportunities for potential candidates to prove themselves. Therefore, small parties may rely more heavily on alternative institutions, such as the EP, to draw candidates for national positions. Additionally, MEPs from small national parties already represent some of the most experienced politicians their parties have. These experienced politicians are likely to be tapped for national service. Therefore, we expect that MEPs from small national parties will be more likely to defect from group votes than MEPs from large national parties.

\subsubsection{Party's Presence in Government}

Whether the MEP's party participates in government at the national level affects the MEP's calculations. Holding a legislative post in a party that serves in government makes a domestic level career goal an attractive option. Sitting with a party in power translates to a greater chance of affecting policy and holding a plum government position. At the same time, if the party serves in government, it increases the competition for party nominations, making it less likely that an MEP could successfully jump back into national politics.

The governing status of the MEP's home party has another influence on MEP behavior. 
When an MEP's national party serves in government, party ministers participate in the European Council, the institution where member states bargain directly over policy. Many bills that come before the EP, therefore, have been vetted by the Council and, as a result, already have the national governing party's approval. An MEP who wishes to return home has incentives to support bills that have been approved by the home party. Indeed, work on voting in the EP suggests that votes frequently split between "parties represented in the [European] Council voting one way and parties not voting in the Council voting the other way" (Hix, Noury \& Roland 2006, 509). In this situation, both group and national party pressures align to encourage the maintenance of group discipline. Therefore, we predict that MEPs are less likely to defect when their home party serves in the government.

\subsection{Member State Characteristics}

\subsubsection{National Elections}

National elections structure the timing of any potential return to domestic office. ${ }^{5}$ As elections approach, parties can call MEPs home to serve as candidates. For politicians using the $\mathrm{EP}$ as a stepping-stone to domestic positions, therefore, it is important to please national parties and domestic constituents in the period leading up to elections. MEPs who are confident that they will enter national office will value the preferences of their expected future constituents above directions from group leaders. We expect nationally ambitious MEPs to vote against their groups more frequently in the run-up to national elections, especially on legislation that expands EU power.

\subsubsection{Electoral System}

The electoral system conditions the nature of an MEP's future constituents. MEPs seeking a return to proportional representation systems have their fate controlled almost entirely by party leaders. Ambitious politicians who wish to return home to a country with a majoritarian electoral system, on the other hand, must satisfy both their party leaders, who 
will choose whether and where to run them, and local voters, who will decide whether to vote for them. These MEPs should be especially focused on ensuring member state benefits in order to win future elections in particular home districts, rather than supporting supranational institutions. ${ }^{6}$ Such MEPs will have frequent reason to vote against their group leaderships, especially on legislation where EP leaders and national constituencies are likely to have differences of opinion, such as measures expanding the influence of the EU.

\section{Data}

To evaluate how political ambition shapes MEPs' voting behavior, we collected data on each roll-call vote in the 5th term of the European parliament (1999-2004). We supplemented the basic voting records with descriptions of the bills considered by the MEPs, information about the votes themselves, MEP biographies, and data describing the political situations in the MEPs' home parties and nations.

\subsection{Roll Call Votes and Bill Descriptions}

We collected roll call tallies from the Official Journal of the European Union (European Union 2006). These data consist of yes-votes, no-votes, and abstentions recorded by a total of $875 \mathrm{MEPs}^{7}$ participating in each of 5778 roll call votes.

The Official Journal provides identifying bill codes for 5644 of these votes, covering 670 unique pieces of legislation. By cross-referencing these identifiers with the EP's online Legislative Observatory (OEIL) (European Parliament 2006a) we obtained four-level descriptive codes of bill issue areas. For the purpose of this project, we focus on only the first level of the issue coding, grouping the bills into eight issue areas: citizens' rights, internal market, agricultural fisheries and economies, economic and social cohesion, economic and monetary system, common foreign and security policy, justice, and the state and evolution of the Union. The last classification listed here, the state and evolution of the Union, is key to our analysis. These "European integration" bills have the potential to expand EU influence over 
member states and should often split group leaderships and nationally ambitious MEPs.

Finally, we augmented our data with Hix, Noury \& Roland's (2006) measures of the EP group sponsoring the roll call vote and the voting rule - simple or absolute majoritygoverning the vote.

\subsubsection{Dependent Variable: Group Vote Defections}

Our dependent variable, voting defections, is not directly recorded in our data set. To operationalize this variable, we first constructed a technique for measuring group votes, those votes which a given EP parliamentary group values highly, and on which it is thus unlikely to lightly tolerate member deviation. Following Cox \& McCubbins (1993, 145-147) we use group leader activity to assess the importance of votes across groups. When the group leadership votes in unison, it stands to reason that they expect the rank and file to fall in line. Therefore, we code each vote at which two thirds of the group leadership attended and at which at least 90 per cent of the attending leaders voted together as a group vote for the given group. ${ }^{8}$ We drop all observations that did not correspond to group votes from the analysis. ${ }^{9}$

Coding defections from group votes is not straightforward due to different voting procedures in the EP. On votes that were decided by simple majority we code only those MEPs that directly voted against their group leaders as defectors, because abstentions have no impact on the outcome of such votes. When MEPs missed simple majority votes altogether, we treat their behavior as a missing value. On absolute majority votes, where abstaining and missing MEPs can affect the outcome, we code MEP behavior as a defection when the group leaders voted nay and the MEP voted yea, or when the MEP voted nay, abstained, or was absent from a pro-measure group vote. ${ }^{10}$ 


\subsection{MEP Characteristics}

We require information describing individual MEP's career situations to explore the connections between legislative voting behavior and political ambition. To this end, we collected biographical data on all 875 MEPs from the EP web site (European Parliament 2006b). We recorded each MEP's age, gender, and nationality. In addition, we collected timevarying ${ }^{11}$ data covering MEPs' EP group membership and leadership positions, and national party membership.

\subsubsection{MEP Ideology}

While ambition theory seeks to explain politicians' behavior in terms of office payoff, ideology also influences their decisions. Therefore, it is important to control for MEPs' underlying policy preferences when examining the behavioral implications of career ambitions. To do so, we employ W-NOMINATE procedures to calculate spatial estimates of legislator ideal points from divisions of roll call votes (Poole \& Rosenthal 1985, Poole 2005). ${ }^{12}$ The first step in the process was to split the set of roll call votes in the 5th parliament in half randomly. We then generated two-dimensional W-NOMINATE scores for each MEP on the first half of the data. ${ }^{13}$ We used these estimates of MEP ideology from the first half of the data to fit our model of vote defection using the second half of the data. As a robustness check, we repeated our analysis, generating W-NOMINATE scores from the second half of the data and using these scores in models fit to the first half. We present only one half of this process here, but results are robust across both orders of operation.

Current research indicates that two voting dimensions separate MEPs: the traditional left-right dimension and a European integration dimension. ${ }^{14}$ We include both measures of ideology in our model. First, we include the first-dimension, left-right position. There is no a priori reason to expect that MEPs from the left will defect at different rates than MEPs on the right. Thus, we do not expect that this variable will have any consistent effect on group defections. 
Second, we include each MEP's NOMINATE score on the second-dimension, support for integration. Higher values on this dimension indicate stronger support for integration and expanding the role of supranational institutions. Lower values suggest a preference for maintaining member-state prerogatives. MEPs who ideologically support European integration vote for supranational prerogatives at a higher rate than those who prefer greater national sovereignty. Because group leaders are generally European careerists and support legislation that expands the power of European institutions, we expect pro-Europe MEPs to vote with the group leadership more often, especially on bills related to European integration.

Finally, for both dimensions, we include a measure of the absolute value of the distance between the individual MEP and the score of the median group member. MEPs who are ideologically distant from their fellow group members are less likely to maintain group discipline than those MEPs who have preferences that are in line with the leadership. Greater distance between the MEP and her group median should translate into a greater probability of defection.

\subsection{National and Home Party System Variables}

We gathered a number of time-varying indicators of domestic member-state politics, including the percentage of legislative seats held by each MEP's home party, national party

cabinet seat percentages, electoral system (majoritarian or proportional representation), and the number of days each MEP expected to pass until her next national election. We coded expected days until national election as the number of days until the election associated with the end of the nation's constitutionally mandated election period (CMEP). In cases with early elections, we coded expected days until national elections in terms of the CMEP until the date at which the national government announced early elections; at this point we updated the variable to reflect the early election date set by the government. ${ }^{15}$

Table 1 contains descriptive statistics for all variables in the analysis.

[Table 1 about here.] 


\section{Method}

The data set is characterized by a complicated hierarchical panel structure. Our unit of observation is the MEP-vote. The MEP-votes are clustered within EP groups, national parties, and countries. Complicating matters further, national parties are nested within countries, but group members are unevenly distributed across parties and countries; that is, group is crossed with party and nation. Additionally, votes are clustered according to bill. And, of course, votes and bills are crossed with every other level in the analysis. This convoluted clustering makes it easy to generate overly optimistic estimates of the strength of the statistical relationships between variables. It confronts us with difficult choices about which hierarchical levels to model explicitly and which groupings to control for statistically.

Binary response models (BRMs) are useful tools for analyzing the relationships between our hypothesized determinants of career ambition and MEP defections (Long 1997). Nonetheless, a basic BRM cannot adequately model the hierarchical nature of our data without a number of modifications. First, we include a battery of dummy variables to model the marginal effects of EP group, national party, and country on MEP deviation probability, effectively dealing with these aspects of the complicated nesting structure in our data by brute force.

It is more difficult to model the data's panel structure. We observe the behavior of each of $M$ MEPs repeatedly across each of $V$ roll call votes (RCVs), with some subset of the MEPs voting on each vote. It is reasonable to expect substantial variation in defection tendency across MEPs, even after explicitly modeling determinants of political ambition: idiosyncratic differences among MEPs influence their voting behavior. Further, there is likely to be variation in defection rates across roll-call votes: some RCVs are far more contentious than others. Unfortunately, a simple fixed effects approach - where the analyst includes dummy variables for each of the $M$ observational units (MEPS) and/or each of the $V$ observations (RCVs) - will not work in this case. Even if we were to follow standard panel data conventions and include fixed effects only for units, the sheer number of parameters 
involved would prove an insurmountable obstacle. Perhaps more importantly, fixed effects BRMs generate biased parameter estimates when $V$ is fixed and $M \rightarrow \infty$ (Neyman \& Scott 1948, Lancaster 2000, Hsiao 2003). But, if we do not take these two important sources of variation into account, we will underestimate the standard errors of our coefficients of interest(Guo \& Zhao 2000).

To overcome this problem, we estimate two-way random effects models (see e.g., Baltagi 2005), otherwise known as crossed random effects models (CREMs). The dataset contains $i=1, \ldots, N$ observations, with each $y_{i}$ recording the behavior of a single MEP on a given vote. When the MEP defects on the vote, $y_{i}=1$ and it equals zero otherwise. We model the probability of MEP defection on group votes using probit CREMs of the form

$$
\begin{aligned}
\operatorname{Pr}\left(y_{i}=1 \mid \boldsymbol{\beta}, \zeta_{m(i)}^{(m)}, \zeta_{v(i)}^{(v)}\right) & =\Phi\left[\mathbf{x}_{i} \boldsymbol{\beta}+\zeta_{m(i)}^{(m)}+\zeta_{v(i)}^{(v)}\right], \\
\zeta_{m(i)}^{(m)} & \sim \mathrm{N}\left(0, \sigma_{m}^{2}\right), \\
\zeta_{v(i)}^{(v)} & \sim \mathrm{N}\left(0, \sigma_{v}^{2}\right)
\end{aligned}
$$

where $\mathbf{x}_{\mathbf{i}}$ is the vector of observed values of the fixed predictors - including group, party, and country dummies - for observation $i, \boldsymbol{\beta}$ is a vector of fixed coefficients to estimate, $\boldsymbol{\zeta}^{(m)}$ and $\zeta^{(v)}$ are vectors of random intercepts for each of the $M$ MEPs and and $V$ RCVs, respectively, ${ }^{16} \sigma_{m}^{2}$ represents the between-MEP variance while $\sigma_{v}^{2}$ corresponds to the between-RCV variance. This approach uses MEP- and RCV-specific intercepts to capture the unmodeled role of individual MEP and RCV characteristics in the probability that a particular MEP defects on a given vote. It assumes that these effects are drawn from a pair of independent normal distributions. This amounts to the assumption that both MEPs and RCVs represent independent draws from large populations with fixed within-population variances.

CREMs are especially difficult to estimate when the models contain binary response variables. Nonetheless, there exist both frequentist maximum likelihood based techniques and Bayesian approaches to estimating these models. Maximum-likelihood based methods for CREM estimation fall into two broad categories, quasi-likelihood estimation and exact max- 
imum likelihood estimation, while Bayesian procedures are based on Markov chain Monte Carlo (MCMC) methods. Rodriguez \& Goldman (2001) show that MCMC and exact maximum likelihood estimation techniques outperform quasi-likelihood approaches in random effects BRM estimation and provide evidence that quasi-likelihood estimation underestimates both fixed and random effects when random effects are substantial. Furthermore, exact maximum likelihood estimation is extremely computationally expensive, rendering its use impractical with our large dataset. Therefore, we use MCMC methods to estimate our models. The appendix provides specific estimation details.

\section{Results}

[Table 2 about here.]

Table 2 displays the results of three random effects models examining the relationship between ambition and roll call voting behavior in the EP. Model 1 is a baseline main effects model and operationalizes age continuously. Models 2 and 3 use a trichotomous operationalization of age to investigate the interactions between age and other variables. The estimates of the MEP and vote random intercept variances, $\sigma_{m}^{2}$ and $\sigma_{v}^{2}$, are consistent across all three models. In each case, the total proportion of the error variance explained by individual random intercepts is about four per cent, while vote random intercepts explain almost 20 per cent of the variance. These findings reflect the fact that our covariates directly model a variety of individual factors - such as ideology — while vote-specific factors are largely absent from the specifications. Table 3 presents deviance information criteria (DICs) ${ }^{17}$ for our three fixed covariate specifications, across a variety of possible statistical approaches, including basic probit models with no random intercepts, 1-way random intercepts models for both MEPs and votes, and CREMs. These statistics indicate that the CREMs fit the data best and that this improvement in fit outweighs the added complexity of these models. The DICs further emphasize the importance of explicitly modeling variation across both MEPs 
and votes: while the MEP random intercepts significantly improve model fit, including the vote intercepts generates a more substantial improvement in predictive accuracy. Finally, the DICs indicate that Model 3 fits the data best, but the difference in fit across the three specifications is minimal.

[Table 3 about here.]

Overall, the average MEP is unlikely to deviate on the average group-vote. Indeed, only $3.8 \%$ of the observations in the dataset represent defections. It is important to note that the predicted effects scale with the baseline probability of defection for a given MEP-vote. That is, for an average observation with a low probability of defection, many covariate effects are substantively modest. Nevertheless, for an MEP-vote where the baseline probability of defection is high, the predicted effects can be quite substantial, several orders of magnitude higher than the average. ${ }^{18}$

We first turn to the results in Model 1. We argue that age is a key determinant of ambitious behavior in the EP. The effect of age is negative and statistically significant while the squared term is positive and statistically significant, indicating a U-shaped relationship between age and vote defection. As hypothesized, the effect of age on vote defection is curvilinear.

Figure 1 displays Model 1's average within-sample predictions for the probability of defection as a function of age. ${ }^{19}$ Middle-aged MEPs are the least likely to vote against their leaders with the likelihood of defection minimized in an MEP's mid-fifties. And, as MEPs get progressively younger - especially below 40 - and older - especially above 65-they become more likely to deviate on group votes. This finding is consistent with progressive ambition theory: young MEPs are more likely to deviate from the group in their pursuit of national careers, middle-aged MEPs maximize their chances in the EU by pleasing the leadership, and older MEPs serve only themselves.

[Figure 1 about here.] 
The effect of gender is statistically insignificant, indicating little difference in vote deviationand perhaps ambition structure - across men and women. Left-right ideology, on the other hand, is statistically significant. Somewhat surprisingly, MEPs with right-wing leanings show a marked propensity for disregarding their group leaders' directions even after controlling for nation, party, EP group, and integration ideology. This may reflect policy differences across different right parties in the member states - liberal parties and Christian Democratic parties often have different economic and social policy preferences. The parameter estimate for integration ideology is negative and significant. As hypothesized, MEPs who value European integration and who presumably also value careers at the European level, are less likely to defect on group votes than other MEPs. This effect is substantial: the average predicted probability of defection for an MEP with an integration ideology score one standard deviation above the EP mean is between 1.6 and 3.4 times less than that of an MEP with a score one standard deviation below the mean. ${ }^{20}$ Finally, as expected, the distance between an MEP's ideal point on the left-right dimension and that of her group's median member strongly predicts vote deviation. Serving as a group leader also significantly decreases the probability of defection.

National characteristics also influence MEP vote deviation in a manner consistent with ambition theory. The coefficient for time until an expected national election is negative and statistically significant, indicating that as the time until the next election decreases, the probability of an MEP defection increases. Clearly, the behavioral implications of future office expectations change over time. Legislators focus their energies on progression within their current institution when no immediate chance to jump ship presents itself; only as potential career changes draw near do MEPs position themselves for the future.

The results also support our expectations about the relationship between national-level party characteristics and MEP behavior. The results indicate a statistically significant negative relationship between national party size - in terms of percentage of legislative seatsand MEP defection on group votes. This finding is consistent with the idea that small party 
MEPs represent an attractive pool of candidates to their national party leaders while MEPs from large parties are operating in a legislative hinterland, under the radar of their national parties who draw from other sources when promoting candidates. Additionally, MEPs representing national parties with strong cabinet presences are less likely to vote against group leadership than MEPs from opposition parties or parties with only a small stake in government. ${ }^{21}$ This result lends credence to the hypothesis that the agenda-setting power available to national governments through the European Council may influence the legislative behavior of MEPs: MEPs from national parties that are in government may pursue both national and supranational career ambitions simultaneously by supporting Council legislation.

Finally, we include three variables to capture the nature of the roll-call vote. The parameter estimate for European integration bills is positive and significant, indicating that MEPs are more likely to defect on these bills than on bills in other substantive areas. The statistically significant coefficients for absolute majority votes indicate that MEPs defect more on these votes than on those conducted under simple majority rule. This result may in part stem from our operationalization of defection, which counts missing MEPs as defectors on absolute majority votes but not on simple ones. Absolute majority votes are also generally employed for more substantial pieces of legislation, such as bills operating under the codecision procedure. MEPs defecting for reasons of ambition have reason to focus their behavior around especially important and visible votes. Lastly, the models indicate that MEPs are more likely to deviate on roll call votes called by their own groups than on those requested by other factions. This result is somewhat surprising, but it may indicate that EP group leaders call RCVs precisely when they expect dissent in the rank and file.

Model 2 extends the analysis of age in Model 1 to examine how an ambitious politician's age interacts with the institutional and voting environment when influencing group vote defection. Model 2 uses dummy variables for young and old MEPs, instead of continuous operationalizations of age and its square, to aid in the estimation and interpretation of these age interactions. Based on the results in Model 1, we classify MEPs as young when they are 
40 years old or less and old when they are 65 or greater. ${ }^{22}$ We interact the age dummies with national election time and European integration bills. The estimates for the main effects remain similar to those in Model 1.

[Figure 2 about here.]

Figure 2 presents the overall relationship between age, bill type, time until national election, and vote defection graphically, in terms of average predicted probabilities from Model 2. The solid lines in Figure2 2 represent middle-aged MEPs, the dashed lines correspond to the defection probabilities of younger MEPs, and the dotted lines display predictions for older MEPs. The gray lines describe predicted behavior when MEPs vote on European integration bills, while black lines predict defections on all other bills.

The results indicate that young MEPs are responsive to variations in bill type and national election timing. The average young MEP's predicted probability of defection is between 0.1 and 1.7 points higher for European integration bills than others, when elections are 870 days away (the dataset mean). For a young MEP with a high baseline defection rate, the probability of defecting on a European integration bill is as much as 14 points higher than on a non-integration bill. For middle-aged and older MEPs, the type of bill has substantially smaller predicted impacts.

The results also predict that a young MEP is between 1.1 and 1.9 times as likely to defect on a group vote right before a national election than three-and-a-half years before an election. Again, the national election proximity effects for middle-aged and older MEPs are more modest. For middle-aged MEPs, national election proximity has a slight, statistically significant effect on the probability of defection, but old MEPs do not respond to national election timing.

For all types of bills, therefore, young MEPs time their defections, focusing their deviations to coincide with national elections. Further, younger MEPs defect more often on European integration bills. The predicted defection rate is significantly higher for integration 
bills than non-integration bills. That is, young MEPs focus their vote defections on exactly those pieces of legislation that are most likely to erode the powers of national political offices and displease national constituents and party functionaries.

Our predictions about when and how older MEPs defect also bear fruit. Unlike their younger counterparts, old MEPs have little incentive to consider the timing of national elections when pursuing their career goals. The predicted probability of defection for an older MEP does not differ significantly across expected national election times. On the other hand, the hypothesis that old MEPs will jealously guard the power of EU institutions because they are likely to remain in them for the rest of their careers is not so clearly supported by the model's results. Unlike their younger colleagues, old MEPs defect somewhat less on integration bills, but those differences are not statistically significant.

Figure 3 breaks down the information in Figure 2 via pairwise comparisons, allowing us to evaluate the interactive influence of age, bill type, and national election timing on vote defection more precisely. The solid lines in Figure 3 are the point estimates of the average probability of defection presented in Figure 2 while the dashed lines are $95 \%$ credible intervals. Black lines represent middle-aged MEPs, gray lines correspond to young MEPs, and light gray lines depict older MEPs' predicted behavior. The top row of panels depict average predicted probabilities for votes on European integration bills while the bottom set of panels represent votes on other bills.

[Figure 3 about here.]

Panels a and b show that young MEPs are significantly more likely to defect on integrationfocused votes than both middle-aged and older MEPs, especially as national elections near. On non-integration bills, however, voting behavior across the age cohorts is different. While panel d indicates the probability of defection on non-integration bills differs significantly between young and middle-aged MEPs throughout their national election cycles, panel e shows that young and old MEPs differ in their predicted defections only as elections approach. 
Panels c and f compare middle-age and old MEPs. On integration bills (panel c), the predicted defection rates for middle-age and old MEPS is statistically indistinguishable. For non-integration bills (panel f), however, old MEPs are significantly more likely to defect when elections are not imminent.

These results imply that younger and middle-aged MEPs drive the integration interaction effects in Model 2. Younger MEPs react strongly to both bill type and election timing. Similarly, middle-aged MEPs react in a statistically significant manner to both election timing and bill type, but at lower substantive levels. This finding is consistent with the possibility that a relatively small number of middle-aged MEPs still covet national office. Older MEPs, on the other hand, cruise along at a steady predicted probability of defection, ignoring integration bills in addition to election timing.

Finally, Model 3 extends Model 2 to investigate the impact of electoral system on MEP voting. Again, the estimates for the main effects remain similar across models. We hypothesized that MEPs from nations holding majoritarian elections would exhibit a greater sensitivity to national prerogatives than their counterparts in proportional representation (PR) systems, especially on legislation dealing with EU expansion. The statistically significant and positive coefficients for majoritarianism and the interaction between majoritarianism and European integration bills in Model 3 support this hypothesis. This effect is also substantively significant; on European integration votes, a majoritarian MEP is between 1.8 and 6.3 times more likely to defect than an MEP from a PR or mixed system, on average.

\section{Conclusion}

By taking advantage of the unique institutional structure of the EP, we are able to identify how different career paths shape behavior while holding the legislative agenda and macropolitical conditions constant. Our results support the primary pillar of ambition theory: MEPs are forward-looking. Young MEPs have the largest potential to return to national politics and are more likely than their colleagues to contravene the dictates of EP group 
leaders. But the relationship between ambition and behavior is not simply a function of a politician's stage in life; the political opportunity structure also shapes how MEPs vote. National election timing, size and governing status of the national party, and the electoral system all shape incentives to defect from group votes. Perhaps most importantly, ambitious MEPs position themselves for national careers in a focused manner, breaking with EP leaders on legislation that determines the relative strengths of EU and national institutions. That is, their career goals lead them to work to the detriment of their current office since they believe that the resulting long-run distribution of power will benefit them more.

Substantively, the results imply a link between the candidate nomination strategies of national-level parties and the pace of integration in the EU. Parties have two basic nomination choices for European elections. First, they can use European elections as a dumping ground for candidates who have little future in national politics. For instance, they can nominate older politicians to the EP, rewarding them with "retirement" positions. Or parties can try to kick difficult and undisciplined national-level politicians upstairs to the EP. As MEPs, however, these politicians have little incentive to preserve member state powers and will instead support increased authority for supranational institutions. Alternatively, parties can use European elections as a proving ground for young politicians. These parties take the work of the EP seriously and value service there as an important stepping-stone to a national career. Ironically, it is the MEPs from these parties who have the most incentive to weaken Europe's supranational institutions in favor of member state prerogatives. As service in the EP becomes more useful for many nationally-ambitious politicians, therefore, pressure to expand the powers of European institutions generally, and the EP specifically, will decrease. Developing a fuller theory of candidate nomination strategies and empirically tracing the careers of individual MEPs will help identify the causal relationships between progressive ambition, legislative behavior, and European integration.

Further, ambition politics within the EP may shape interactions between EU institutions. Our results indicate that incentives for defection vary according to the timing of national- 
level elections. As a national election draws near, MEPs from that member state are more likely to defect from their group. This raises the possibility of agenda manipulation by the Commission, which initiates all European legislation, and the Council, the institution for direct member state bargaining. The Commission and the Council may attempt to time the delivery of legislative bills to the EP to take advantage of MEP's incentives. The Commission may delay pro-integration legislation until just after a national election in a key memberstate as a way to insure the most support. Alternatively, the Council might send pro-member state bills to the EP as national elections approach. Our results, therefore, suggest that it might be possible to link episodes of conflict between the Commission and the Council to the timing of national elections.

Finally, the results have broader implications for the study of legislative behavior. From a theoretical perspective, we highlight the importance of political ambition in determining behavior. Other research emphasizes the importance of ideology in shaping vote choice, relying on the same voting records to generate estimates of legislators' ideal points (Hix, Noury \& Roland 2006). Yet, in isolation, neither of these factors can adequately explain legislative voting. Just as we incorporated ideology in our model of political ambition, so too must one explicitly model ambition when extracting ideological content from votes. Disentangling the influence of ideology and ambition represents a challenge not only for the study of the EP, but for legislative studies more generally. By doing so, we may very well reveal very different maps of the ideological space of legislative behavior.

\section{Appendix}

Bayesian CREM estimation requires the analyst to specify prior probability distributions for the model parameters $\boldsymbol{\beta}, \sigma_{m}^{2}$, and $\sigma_{v}^{2}$ in Equation 1. Following Browne \& Draper (2000) and Browne, Goldstein \& Rabash (2001), we adopt a diffuse multivariate normal prior for the $p$ fixed effects, $\boldsymbol{\beta} \sim \mathrm{N}_{p}\left(\boldsymbol{\mu}_{0}, \boldsymbol{\Sigma}_{0}\right)$, where $\boldsymbol{\mu}_{0}=0$ and $\boldsymbol{\Sigma}_{0}=10^{6} \mathbf{I}$. Similarly, we select scaled inverse $\chi^{2}$ priors for the variance terms, $\sigma_{m}^{2} \sim \operatorname{SI} \chi^{2}\left(v_{m}, s_{m}^{2}\right)$ and $\sigma_{v}^{2} \sim \operatorname{SI} \chi^{2}\left(v_{v}, s_{v}^{2}\right)$, where 
$v_{m}=v_{v}=2 \cdot 10^{-3}$ and $s_{m}^{2}=s_{v}^{2}=1$. By choosing these prior distributions we indicate that we are uncertain about $\boldsymbol{\beta}$ and assume that the random intercepts are all close to zero, a priori.

Rabash \& Browne (In Press) describe a Gibbs sampling algorithm for estimating a CREM with continuous responses. We take advantage of the latent variable interpretation of binary regression and a data augmentation (Tanner \& Wong 1987) technique introduced by Albert \& Chib (1993) to convert this continuous response estimation algorithm into one that can estimate the BRM in Equation 1. This algorithm treats the random intercepts $\boldsymbol{\zeta}^{(m)}$ and $\boldsymbol{\zeta}^{(v)}$ as latent variables and introduces a new vector of latent variables $\mathbf{z}$, such that

$$
z_{i}=\mathbf{x}_{\mathbf{i}} \boldsymbol{\beta}+\zeta_{m(i)}^{(m)}+\zeta_{v(i)}^{(v)}+\epsilon_{i}
$$

where we assume each independent and identically distributed $\epsilon_{i} \sim \mathrm{N}(0,1)$ and

$$
y_{i}= \begin{cases}0 & \text { if } z_{i} \leq 0 \\ 1 & \text { if } z_{i}>0\end{cases}
$$

This is the familiar latent variable specification of the probit BRM and implies that

$$
\operatorname{Pr}\left(y_{i}=1 \mid \boldsymbol{\beta}, \zeta_{m(i)}^{(m)}, \zeta_{v(i)}^{(v)}\right)=\Phi\left[\mathbf{x}_{i} \boldsymbol{\beta}+\zeta_{m(i)}^{(m)}+\zeta_{v(i)}^{(v)}\right]
$$

or, in other words, the latent variable specification in equations 2 and 3 is equivalent to the binary response CREM described by Equation 1. This parameterization of the model in Equation 1 suggests a Gibbs sampling algorithm ${ }^{23}$ that incorporates the following steps in each iteration $\left(n_{k}^{(c)}\right.$ is the number of observations in the $k$ th unit of classification $c, n_{m}$ is the number of MEPs and $n_{v}$ is the number of votes):

1. Simulate $\boldsymbol{\beta}$ from $f\left(\boldsymbol{\beta} \mid \mathbf{z}, \sigma_{m}^{2}, \sigma_{v}^{2}, \boldsymbol{\zeta}^{(m)}, \boldsymbol{\zeta}^{(v)}\right) \sim \mathrm{N}_{p}(\hat{\boldsymbol{\beta}}, \hat{\mathbf{D}})$, where 
- $\hat{\mathbf{D}}=\left[\mathbf{X}^{\prime} \mathbf{X}+\boldsymbol{\Sigma}_{0}^{-1}\right]^{-1}$

- $\hat{\boldsymbol{\beta}}=\hat{\mathbf{D}}\left[\sum_{i=1}^{N} \mathbf{x}_{i}^{\prime} d_{i}+\boldsymbol{\Sigma}_{0}^{-1} \boldsymbol{\mu}_{0}\right]$

- $d_{i}=z_{i}-\zeta_{m(i)}^{(m)}-\zeta_{v(i)}^{(v)}$

2. Simulate each $\zeta_{k}^{(m)}$ from $f\left(\zeta_{k}^{(m)} \mid \mathbf{z}, \boldsymbol{\beta}, \sigma_{m}^{2}, \sigma_{v}^{2}, \boldsymbol{\zeta}^{(v)}\right) \sim \mathrm{N}\left(\hat{\mu}_{k}^{(m)}, \hat{D}_{k}^{(m)}\right)$, where

- $\hat{D}_{k}^{(m)}=\left[n_{k}^{(m)}+\frac{1}{\sigma_{m}^{2}}\right]^{-1}$

- $\hat{\mu}_{k}^{(m)}=\hat{D}_{k}^{(m)}\left[\sum_{i \text { s.t } m(i)=k}\left(z_{i}-\mathbf{x}_{\mathbf{i}} \boldsymbol{\beta}-\zeta_{v(i)}^{(v)}\right)\right]$

3. Simulate each $\zeta_{k}^{(v)}$ from $f\left(\zeta_{k}^{(v)} \mid \mathbf{z}, \boldsymbol{\beta}, \sigma_{m}^{2}, \sigma_{v}^{2}, \boldsymbol{\zeta}^{(m)}\right) \sim \mathrm{N}\left(\hat{\mu}_{k}^{(v)}, \hat{D}_{k}^{(v)}\right)$, where

- $\hat{D}_{k}^{(v)}=\left[n_{k}^{(v)}+\frac{1}{\sigma_{v}^{2}}\right]^{-1}$

- $\hat{\mu}_{k}^{(v)}=\hat{D}_{k}^{(v)}\left[\sum_{i \text { s.t } v(i)=k}\left(z_{i}-\mathbf{x}_{\mathbf{i}} \boldsymbol{\beta}-\zeta_{m(i)}^{(m)}\right)\right]$

4. Simulate $\sigma_{m}^{2}$ from $f\left(\frac{1}{\sigma_{m}^{2}} \mid \mathbf{z}, \boldsymbol{\beta}, \sigma_{v}^{2}, \boldsymbol{\zeta}^{(m)}, \boldsymbol{\zeta}^{(v)}\right) \sim \operatorname{Gamma}\left[\frac{n_{m}+v_{m}}{2}, \frac{1}{2} \sum_{j=1}^{n_{m}}\left(\zeta_{j}^{(m)}\right)^{2}+v_{m} s_{m}^{2}\right]$

5. Simulate $\sigma_{v}^{2}$ from $f\left(\frac{1}{\sigma_{v}^{2}} \mid \mathbf{z}, \boldsymbol{\beta}, \sigma_{m}^{2}, \boldsymbol{\zeta}^{(m)}, \boldsymbol{\zeta}^{(v)}\right) \sim \operatorname{Gamma}\left[\frac{n_{v}+v_{v}}{2}, \frac{1}{2} \sum_{j=1}^{n_{v}}\left(\zeta_{j}^{(v)}\right)^{2}+v_{v} s_{v}^{2}\right]$

6. Simulate each $z_{i}$ from the truncated normal distributions

$$
f\left(z_{i} \mid y_{i}, \boldsymbol{\beta}, \sigma_{m}^{2}, \sigma_{v}^{2}, \zeta_{m(i)}^{(m)}, \zeta_{v(i)}^{(v)}\right) \sim \begin{cases}\mathrm{N}_{(0, \infty)}\left(\mathbf{x}_{i} \boldsymbol{\beta}+\zeta_{m(i)}^{(m)}+\zeta_{v(i)}^{(v)}\right) & \text { if } y_{i}=1 \\ \mathrm{~N}_{(-\infty, 0)}\left(\mathbf{x}_{i} \boldsymbol{\beta}+\zeta_{m(i)}^{(m)}+\zeta_{v(i)}^{(v)}\right) & \text { if } y_{i}=0\end{cases}
$$

This algorithm directly simulates from the posterior distributions of not only the fixed coefficients and random effects variances but also from the posteriors of all three sets of latent variables, allowing the analyst to work with the estimated posterior distributions of the random intercepts and to perform residual analysis based on $\mathbf{z}$ using familiar techniques from linear regression modeling.

In our analysis of MEP voting behavior, we estimated each model by running the Gibbs sampler for 55,000 iterations, discarding the first 5,000 iterations and retaining every 50th 
iteration for a final posterior sample of 1,000 observations. Standard diagnostic tests generated results consistent with chain convergence for all three models and results are robust to variation in chain starting values and prior specification. In addition, penalized quasilikelihood estimates of logistic versions of these models produce substantively similar results to the MCMC probit approach. We performed all MCMC computation in $\mathrm{C}++$ using the Scythe Statistical Library (Pemstein, Quinn \& Martin 2007).

\section{Notes}

${ }^{1}$ Over-time analysis provides one technique for overcoming this shortcoming, and such research has helped to explain phenomena like the rise of careerism in American politics (Brady, Buckley \& Rivers 1999).

${ }^{2}$ The EP was established in 1957. Direct election to the EP, however, commenced only in 1979. Before this it was composed of appointed national delegations.

${ }^{3}$ This was particularly true prior to the advent of the Codecision procedure. Codecision, introduced with the Treaty of Maastricht in 1993, greatly increased the powers of the EP and with it the prestige and importance of EP positions.

${ }^{4}$ Although the use of quota systems at the party or national levels create more slots for women in domestic politics, it is not clear that those opportunities will affect the legislative behavior of women MEPs. Electoral quotas expand the demand for women candidates, while the pool of "quality" women candidates (i.e., those with some sort of experience holding political office) is likely to be small. Therefore, parties may choose women as candidates even if those women have not done as much to serve the interests of the party. Women MEPs interested in a career in domestic politics, therefore, do not necessarily face the same behavioral incentives as male MEPs with the same ambitions.

${ }^{5}$ National elections provide important opportunities to return to national politics for MEPs from all member states. In some member states, local or regional elections may also provide the possibility of domestic office. Nonetheless, because the importance of these 
local and regional opportunities varies considerably across member-states, we leave a direct analysis of their impact to future research.

${ }^{6}$ Scholl (1986) argued a similar logic and showed that British MEPs coming from majoritarian European Parliament districts (before the elimination of those districts in the 1990s) were markedly more constituency and nationally oriented than their PR counterparts.

${ }^{7}$ Although 875 MEPs served in the EP over the course of the 5th term, only 626 members were active at any single given point in time. That is, the EP contains 626 members but the composition of the parliament changed over the course of the 5 th term, with 875 MEPs serving in total. We include in the analysis only MEPs representing those countries that were EU members at the beginning of the 5th term: Austria, Belgium, Denmark, Finland, France, Germany, Greece, Ireland, Italy, Luxembourg, The Netherlands, Portugal, Spain, Sweden, and The United Kingdom.

${ }^{8}$ The leadership of a group in the 5 th EP can contain as many as 16 individuals.

${ }^{9}$ Because a given vote can be a group vote for one or two groups but not for others, there are many votes that only influence our results through the actions of a subset of the active MEPs.

${ }^{10}$ Choosing the correct form of the deviation variable was difficult. Missing MEPs, while often simply on vacation or in the restroom, may skip votes in a strategic fashion. We replicated the substantive results of our analysis across four versions of the dependent variable: in addition to the defection variable described in the text we tried coding all missing MEPs as defectors, all missing MEPs as missing values, and missing MEPs on simple majority votes as non-defectors.

${ }^{11}$ All time varying data is at day resolution.

${ }^{12}$ By contrast, other studies use expert placements (e.g. Marks, Wilson \& Ray 2002, Ray 1999) or party manifestos data (Gabel \& Hix 2002, Pennings 2002) to place parties and MEPs on various policy dimensions.

${ }^{13}$ Votes were only incorporated into NOMINATE scores where at least 2.5 per cent of 
voters were in the minority and MEPs were included only if they recorded a minimum of 25 votes

${ }^{14}$ Hix (2001) and Hix, Noury \& Roland (2006) fit models predicting these two primary NOMINATE dimensions with expert evaluations of issue positions and find that "the second dimension is strongly related to the EU integration dimension [of expert evaluations]."

${ }^{15}$ We obtained election and election announcement dates from the European Journal of Political Research and Electoral Studies.

${ }^{16}$ The functions $m(\cdot)$ and $v(\cdot)$ subscripting the random intercept components in Equation 1 map each observation $i$ to its respective MEP and VOTE intercepts. Browne, Goldstein \& Rabash (2001) introduce this notation.

${ }^{17}$ The DIC (Spiegelhalter, Best, Carlin \& van der Linde 2002) is a goodness of fit statistic that, like the Akaike information criterion (AIC) or Bayesian information criterion (BIC), balances a model's fit to data with its complexity, in terms of number of parameters. The DIC is specifically designed for comparing hierarchical models and is especially well suited to Bayesian MCMC models.

${ }^{18}$ The models generate numerous in-sample predictions of the probability of defection in excess of 0.5 .

${ }^{19}$ To compute average within-sample predicted probabilities we calculate the predicted probability of defection for each observation in the dataset and then average the predictions. This produces a representative estimate of predicted effects in contrast to choosing a single "representative" MEP-vote or setting covariates at their means. Because of the size of our dataset, we performed this operation on a random sub-sample of 1000 MEP-votes from the dataset, rather than on all of the data.

${ }^{20}$ Effect ranges are based on $95 \%$ credible intervals around average predicted probabilities. ${ }^{21}$ Although the coefficient for party cabinet percentage only reaches conventional levels of statistical significance in Model 2, Model 1 estimates that the coefficient is negative with probability 0.88 , while the corresponding probability is 0.87 in Model 3 . Therefore, 
the negative relationship between party cabinet percentage and vote defection is generally supported across all three models.

${ }^{22}$ MEPs under 40 represent approximately $12 \%$ of the total while those over 65 include about $5 \%$ of the population. We experimented with age cutoffs at 35 and 60 with similar results.

${ }^{23}$ Gibbs samplers iteratively sample from the posterior distributions of subsets of the model parameters conditional on current simulated values of the remaining parameters - a process that eventually converges to the model parameters' joint posterior distribution. For an introduction to Gibbs samplers, and MCMC in general, see Gelman, Carlin, Stern \& Rubin (2004) or Gill (2002).

\section{References}

Albert, James H. \& Siddhartha Chib. 1993. "Bayesian Analysis of Binary and Polychotomous Response Data." Journal of the American Statistical Association 88(422):669-679.

Baltagi, Badi H. 2005. Econometric Analysis of Panel Data. 3rd ed. Chichester: Wiley.

Black, Gordon. 1972. "A Theory of Political Ambition: Career Choice and the Role of Structural Incentives." American Political Science Review 66:144-159.

Brace, Paul. 1984. "Progressive Ambition in the House: A Probabilistic Approach." The Journal of Politics 46:556-571.

Brady, David, Kara Buckley \& Douglas Rivers. 1999. "The Roots of Careerism in the U.S. House of Representatives." Legislative Studies Quarterly 24(4):489-510.

Browne, William J. \& David Draper. 2000. "Implementation and Performance Issues in the Bayesian and Likelihood Fitting of Multilevel Models." Computational Statistics 15:391-420. 
Browne, William J., Harvey Goldstein \& Jon Rabash. 2001. "Multiple Membership Multiple Classification (MMMC) Models." Statistical Modelling 1:103-124.

Carey, John. 1996. Term Limits and Legislative Representation. New York: Cambridge University Press.

Copeland, Gary. 1989. "Choosing to Run: Why House Members Seek Election to the Senate." Legislative Studies Quarterly 14:549-566.

Cox, Gary, Fraces Rosenbluth \& Michael Thies. 2000. "Electoral Rules, Career Ambitions, and Party Structure: Comparing Factions in Japan's Upper and Lower Houses." American Journal of Political Science 44(1):115-122.

Cox, Gary W. \& Mathew D. McCubbins. 1993. Legislative Leviathan: Party Government in the House. Berkeley: University of California Press.

Epstein, David, David Brady, Sadafumi Kawato \& Sharyn O'Halloran. 1997. "A Comparative Approach to Legislative Organization: Careerism and Seniority in the United States and Japan." American Journal of Political Science 41(3):965-988.

European Parliament. 2006a. "The Legislative Observatory." http://www.europarl. europa.eu/oeil/index.jsp.

European Parliament. 2006b. "Your MEPs." http://www.europarl.europa.eu/members/ archive.do.

European Union. 2006. "Official Journal of the European Union." http://europa.eu.int/ eur-lex/lex/JOIndex.do.

Gabel, Matthew \& Simon Hix. 2002. "Defining the EU Political Space: An Empirical Study of the European Election Manifestos 1979-1999." Comparative Political Studies 35:934964. 
Gelman, Andrew, John B. Carlin, Hal S. Stern \& Donald B. Rubin. 2004. Bayesian Data Analysis. 2nd ed. Boca Raton: Chapman \& Hall.

Gill, Jeff. 2002. Bayesian Methods: A Social and Behavioral Sciences Approach. Boca Raton: Chapman \& Hall.

Guo, Guang \& Hongxin Zhao. 2000. "Multilevel Modeling for Binary Data." Annual Review of Sociology 26:441-462.

Hain, Paul. 1974. "Age, Ambition, and Political Careers: The Middle Age Crisis." Western Studies Quarterly 27:265-274.

Hibbing, John. 1986. "Ambition in the House: The Behavioral Consequences of Higher Office Goals Among US Representatives." American Journal of Political Science 30:651-666.

Hibbing, John. 1999. "Legislative Careers: Why and How We Should Study Them." Legislative Studies Quarterly 24(2):149-171.

Hix, Simon. 2001. "Legislative Behavior and Party Competition in the European Parliament: An Application of Nominate to the EU." Journal of Common Market 39:663-688.

Hix, Simon, Abdul Noury \& Gerard Roland. 2006. "Dimensions of Politics in the European Parliament." American Journal of Political Science 50(2):494-511.

Hsiao, Cheng. 2003. Analysis of Panel Data. 2nd ed. Cambridge: Cambridge University Press.

IPU. 2006. "Women In National Parliaments." http://www.ipu.org/wmn-e/world.htm.

Lancaster, Tony. 2000. "The Incidental Parameter Problem Since 1948." Journal of Econometrics 95:392-413.

Long, J. Scott. 1997. Regression Models for Categorical and Limited Dependent Variables. Thousand Oaks, California: SAGE. 
Marks, Gary, Carole Wilson \& Leonard Ray. 2002. "National Parties and European Integration." American Journal of Political Science 46(3):585-594.

Neyman, Jerzy \& Elizabeth L. Scott. 1948. "Consistent Estimates Based on Partially Consistent Observations." Econometrica 16:1-22.

Pemstein, Daniel, Kevin M. Quinn \& Andrew D. Martin. 2007. "Scythe Statistical Library v1.0.1." http://scythe.wustl.edu.

Pennings, Paul. 2002. "The Dimensionality of the EU Policy Space." European Union Politics 3:59-80.

Poole, Keith T. 2005. Spatial Models of Parliamentary Voting. Cambridge: Cambridge University Press.

Poole, Keith T. \& Howard Rosenthal. 1985. "A Spatial Model for Legislative Roll-Call Analyis." American Journal of Political Science 29(2):357-384.

Rabash, Jon \& William J. Browne. In Press. Non-Hierarchical Multilevel Models. In Handbook of Quantitative Multilevel Analysis, ed. Jan De Leeuw \& I.G.G Kreft.

Ray, Leonard. 1999. "Measuring Party Orientation Towards European Integration: Results from an Expert Survey." European Journal of Political Research 36:283-306.

Rhode, David W. 1979. "Risk Bearing and Progressive Ambition: The Case of the United States House of Representatives." American Journal of Political Science 23:1-26.

Rodriguez, German \& Noreen Goldman. 2001. "Improved Estimation Procedures for Multilevel Models with Binary Response: A Case-Study." Journal of the Royal Statistical Society A 184(2):339-355.

Samuels, David. 2003. Ambition, Federalism, and Legislative Politics in Brazil. Cambridge: Cambridge University Press. 
Scarrow, Susan. 1997. "Political Career Paths and the European Parliament." Legislative Studies Quarterly 22:253-263.

Schlesinger, Joseph A. 1966. Ambition and Politics. Rand McNally.

Scholl, Edward. 1986. "The Electoral System and Constituency Oriented Activity in the European Parliament." International Studies Quarterly 30:315-332.

Spiegelhalter, David J., Nicola G. Best, Bradley P. Carlin \& Angelika van der Linde. 2002. "Bayesian Measures of Model Complexity and Fit." Journal of the Royal Statistical Society B 64(4):583-639.

Squire, Peverill. 1988. "Member Career Opportunities and the Internal Organization of Legislatures." The Journal of Politics 50:726-744.

Stolz, Klaus. 2001. Parliamentary Careers in Europe Between the Regional, National, and Supranational Level. In ECPR Joint Sessions Workshops. Grenoble: .

Tanner, T.A. \& W.H. Wong. 1987. "The Calculation of Posterior Distributions by Data Augmentation." Journal of the American Statistical Association 82:528-549. 
Table 1: Descriptive Statistics

\begin{tabular}{lcccc}
\hline \hline & Mean & Std. Deviation & Minimum & Maximum \\
\hline Age & 53.07 & 9.21 & 23.12 & 79.31 \\
Gender & 0.34 & 0.47 & 0.00 & 1.00 \\
Left-Right Ideology & -0.08 & 0.48 & -0.81 & 0.82 \\
Integration Ideology & 0.26 & 0.53 & -1.00 & 1.00 \\
Left-Right Distance & 0.05 & 0.06 & 0.00 & 0.85 \\
Integration Distance & 0.14 & 0.21 & 0.00 & 1.31 \\
Group Leader & 0.07 & 0.36 & 0.00 & 1.00 \\
Natn'l Election Time & 860.99 & 462.73 & 1.00 & 1824.00 \\
Majoritarian & 0.27 & 0.44 & 0.00 & 1.00 \\
Natn'l Party Seat $\%$ & 26.22 & 15.63 & 0.00 & 63.30 \\
Natn'l Party Cabinet $\%$ & 24.02 & 36.14 & 0.00 & 100.00 \\
Integration Bill & 0.23 & 0.42 & 0.00 & 1.00 \\
Absolute Majority & 0.13 & 0.33 & 0.00 & 1.00 \\
Group RCV Sponsor & 0.19 & 0.39 & 0.00 & 1.00 \\
\hline \hline
\end{tabular}


Table 2: Determinants of Vote Defection in the European Parliament, 5th Term

\begin{tabular}{|c|c|c|c|c|c|c|}
\hline \multirow[b]{2}{*}{$\mathrm{Age}^{\mathrm{a}}$} & \multicolumn{2}{|c|}{ Model 1} & \multicolumn{2}{|c|}{ Model 2} & \multicolumn{2}{|c|}{ Model 3} \\
\hline & -0.3497 & $(0.0646)^{* *}$ & & & & \\
\hline Age Squared & 0.0325 & $(0.0062)^{* *}$ & & & & \\
\hline Young & & & 0.1513 & $(0.0348)^{* *}$ & 0.1496 & $(0.0322)^{* *}$ \\
\hline Old $^{c}$ & & & 0.0419 & $(0.0308)$ & 0.0369 & $(0.0304)$ \\
\hline Gender & -0.0022 & $(0.0207)$ & -0.0036 & $(0.0202)$ & -0.0016 & $(0.0202)$ \\
\hline Left-Right Ideology & 0.4053 & $(0.1418)^{* *}$ & 0.4345 & $(0.1471)^{* *}$ & 0.4298 & $(0.1542)^{* *}$ \\
\hline Integration Ideology & -0.4841 & $(0.1105)^{* *}$ & -0.4872 & $(0.1133)^{* *}$ & -0.4834 & $(0.1105)^{* *}$ \\
\hline Left-Right Distance & 1.0085 & $(0.2119)^{* *}$ & 0.9698 & $(0.2176)^{* *}$ & 0.9522 & $(0.2116)^{* *}$ \\
\hline Integration Distance & 0.0093 & $(0.1374)$ & 0.0203 & $(0.1382)$ & 0.0186 & $(0.1399)$ \\
\hline Group Leader & -0.4096 & $(0.0298)^{* *}$ & -0.4133 & $(0.0299)^{* *}$ & -0.4170 & $(0.0293)^{* *}$ \\
\hline Natn'l Election Time ${ }^{\mathrm{d}}$ & -0.0096 & $(0.0008)^{* *}$ & -0.0092 & $(0.0009)^{* *}$ & -0.0087 & $(0.0009)^{* *}$ \\
\hline Majoritarian & & & & & 0.5740 & $(0.2151)^{* *}$ \\
\hline Natn'l Party Seat \% & -0.0043 & $(0.0014)^{* *}$ & -0.0041 & $(0.0015)^{* *}$ & -0.0045 & $(0.0015)^{* *}$ \\
\hline Natn'l Party Cabinet \% & -0.0005 & $(0.0003)$ & -0.0005 & $(0.0003)^{*}$ & -0.0019 & $(0.0008)$ \\
\hline Integration Bill & 0.0715 & $(0.0238)^{* *}$ & 0.0768 & $(0.0219)^{* *}$ & -0.0019 & $(0.0245)$ \\
\hline Absolute Majority & 0.9995 & $(0.0268)^{* *}$ & 1.0013 & $(0.0260)^{* *}$ & 1.0017 & $(0.0279)^{* *}$ \\
\hline Group RCV Sponsor & 0.0585 & $(0.0112)^{* *}$ & 0.0596 & $(0.0107)^{* *}$ & 0.0598 & $(0.0120)^{* *}$ \\
\hline Young $\times$ Natn'l Election Time & & & -0.0077 & $(0.0029)^{* *}$ & -0.0076 & $(0.0028)^{* *}$ \\
\hline Young $\times$ Integration Bill & & & 0.0470 & $(0.0282)^{*}$ & 0.0385 & $(0.0284)$ \\
\hline Old $\times$ Natn'l Election Time & & & 0.0016 & $(0.0026)$ & 0.0015 & $(0.0025)$ \\
\hline Old $\times$ Integration Bill & & & -0.0906 & $(0.0319)^{* *}$ & -0.0569 & $(0.0312)^{*}$ \\
\hline Majoritarian $\times$ Bill Type 8 & & & & & 0.2276 & $(0.0173)^{* *}$ \\
\hline$\sigma_{m}^{2}$ & 0.0533 & $(0.0036)$ & 0.0533 & $(0.0038)$ & 0.0531 & $(0.0036)$ \\
\hline$\sigma_{v}^{2}$ & 0.2456 & $(0.0086)$ & 0.2454 & $(0.0086)$ & 0.2452 & $(0.0087)$ \\
\hline
\end{tabular}

We present estimated posterior means and, in parentheses, standard deviations. All models include full batteries of fixed effects for EP group, nation, and national party (when more than one MEP represented that party in the 5th EP) and an intercept term (not shown). $M=575$; $V=2124 ; N=621627$.

* The $90 \%$ Bayesian credible interval for this coefficient excludes zero.

** The $95 \%$ Bayesian credible interval for this coefficient excludes zero.

a Age is scaled to tens of years.

b Young MEPs are 40 years old or less.

c Old MEPs are 65 years old or more.

$\mathrm{d}$ Time until national election is scaled to hundreds of days. 
Table 3: Deviance Information Criteria Across Specifications

\begin{tabular}{lccc}
\hline \hline & Model 1 & Model 2 & Model 3 \\
\hline No Random Effects & 180,136 & 180,110 & 179,941 \\
MEP Random Effects Only & 176,763 & 176,740 & 176,567 \\
Vote Random Effects Only & 159,011 & 159,004 & 158,845 \\
Crossed Random Effects & 155,353 & 155,349 & 155,190 \\
\hline \hline
\end{tabular}


Figure 1: Average Predicted Probability of Defection as a Function of Age

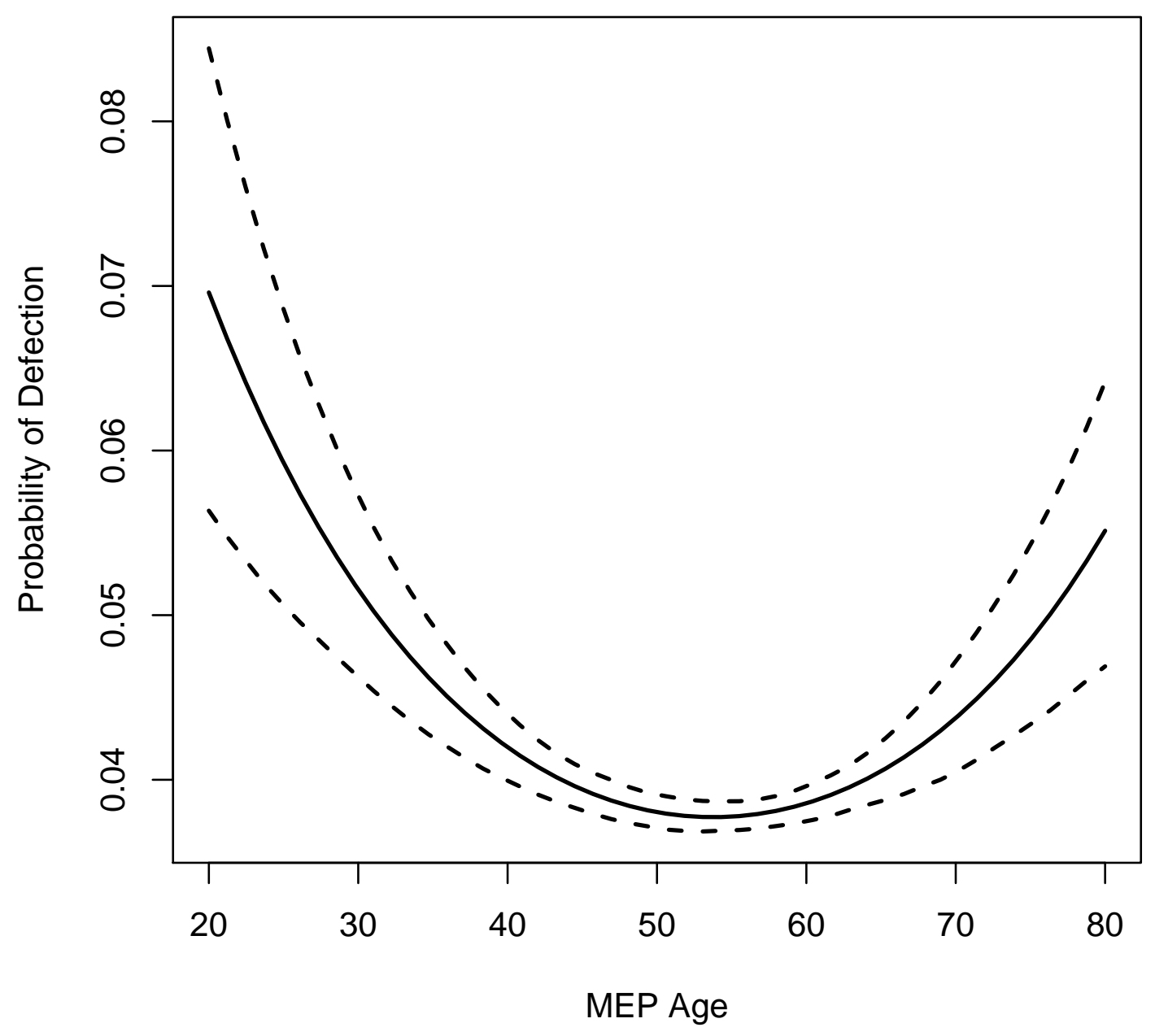


Figure 2: Average Predicted Probability of Defection as a Function of Age, Bill Type, and Proximity of National Elections

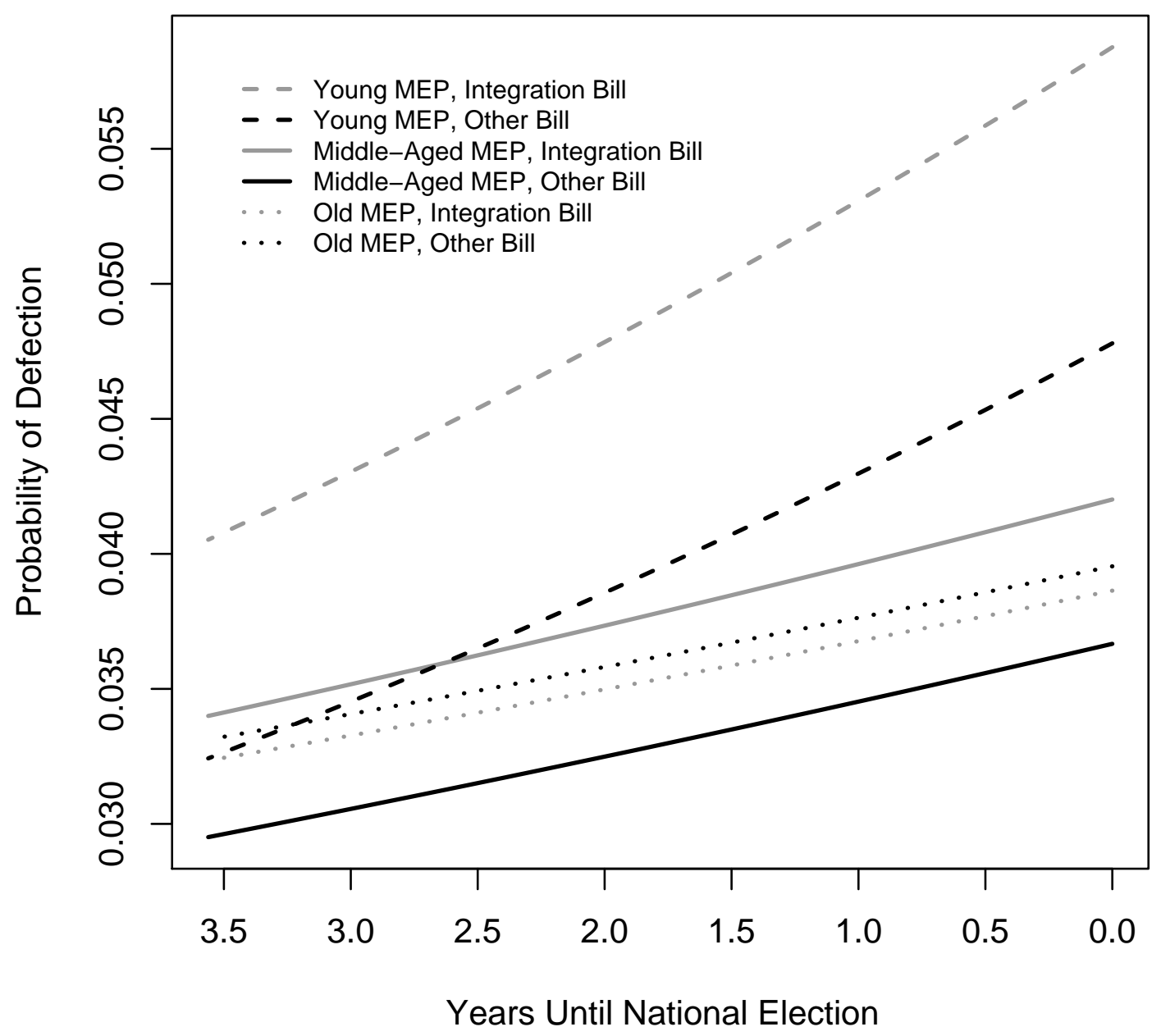


Figure 3: Average Predicted Probability of Defection as a Function of Age, Bill Type, and Proximity of National Elections: Pairwise Comparisons with 95\% Credible Intervals
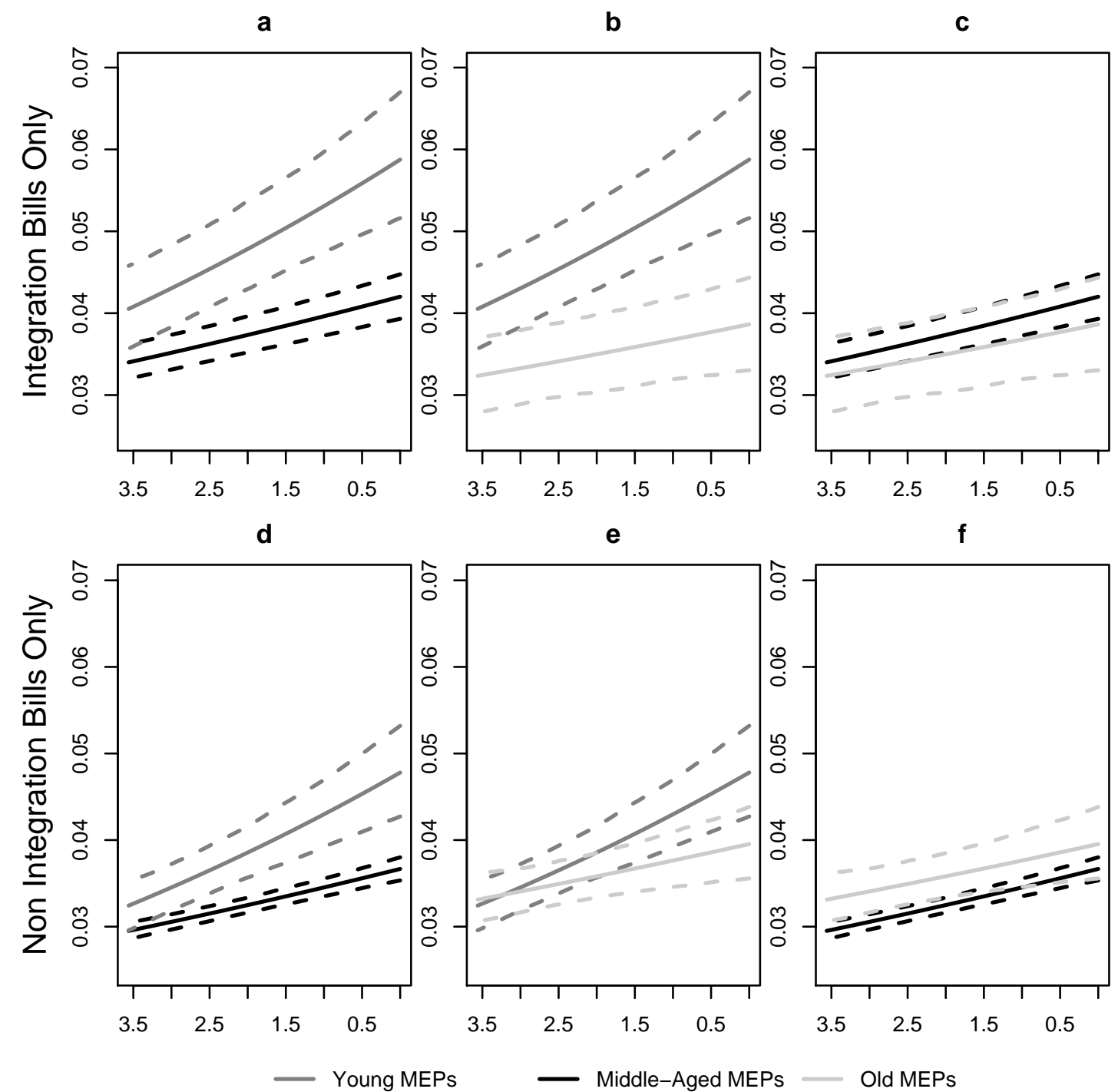